\title{
Impact of the air-entrained concrete with the blast-furnace slag cement on the intensity of reinforcement corrosion process
}

\author{
Wioletta Raczkiewicz ${ }^{1}$, Wioletta Grzmil ${ }^{1, *}$, and Justyna Zapała - Sławeta ${ }^{1}$ \\ ${ }^{1}$ Kielce University of Technology, al. Tysiąclecia Państwa Polskiego 7, 25-314 Kielce, Poland
}

\begin{abstract}
The concrete cover has significant impact on the intensity of reinforcement corrosion process in reinforced concrete elements. Depending on the type of corrosion risk different types of cement are recommended for concrete. In conditions of chloride corrosion, due to, for example, the use of de-icing agents in winter, it is recommended to use concrete with cement containing granulated blast-furnace slag. The risk of chloride corrosion due to the use of de-icing agents is often additionally associated with the frost and repeated freezing and thawing actions of structural elements. The liquid freezing in the pores of concrete increases its volume, which causes the increase of internal stresses and leads to cracks in the concrete cover increasing the diffusion of chlorides. In order to reduce this phenomenon the introduction of air-entraining admixture is beneficial. The paper presents the experimental results that allow to determinate the effect of the air-entraining admixture addition on the intensity of reinforcement corrosion in concrete with blast-furnace slag cement. The tests were carried out on two groups of reinforced concrete specimens subjected to freezing and thawing cycles in $3 \% \mathrm{NaCl}$ solution. One group of specimens was prepared with the airentraining admixture addition and the other without it. The electrochemical tests of the reinforcement corrosion activity, based on the measurements of the corrosion current density were curried. The phase composition by X-ray diffraction and microstructure of concrete under the scanning electron microscope (SEM) coupled with the X-ray microanalyser (EDS) were examined. The results allowed to comprehensively assess the effect of airentrained concrete with blast-furnace slag cement on the degree of reinforcement corrosion risk in concrete caused by the simultaneous action of chlorides and frost.
\end{abstract}

\section{Introduction}

The protection of reinforcement against corrosion is of decisive importance in ensuring the durability of reinforced concrete elements [1-4]. Such protection is ensured by proper and properly made concrete cover, i.e. a cover with appropriate thickness and properties of components [1-6]. Its task is to limit or slow down the penetration of aggressive substances deep into the concrete structure that may damage the passive layer on the reinforcing bars

\footnotetext{
* Corresponding author: wgrzmil@tu.kielce.pl
} 
and initiate the corrosion process. In conditions of chloride corrosion (due to, for example, the use of de-icing agents in winter), it is recommended that reinforced concrete elements are made of concrete with cement containing granulated blast-furnace slag [7-9]. As a result of using blast-furnace slag cement during the hydration a larger amount of the amorphous $\mathrm{C}$ $\mathrm{S}-\mathrm{H}$ gel is formed with a reduced $\mathrm{C}_{3} \mathrm{~A}$ content compared to commonly used Portland cement $[3,8-10]$, the concrete bonding and hardening processes are slower.

The structure of concrete with metallurgical cement is more compact and tight with a lower capillary pore content, which reduces the diffusion of chlorides and due to the lower hydration heat, the shrinkage strains are smaller and slower [3, 8-10]. As a result, the penetration of aggressive substances into the concrete structure is effectively limited. This is particularly important in the case of extremely aggressive and pitting chloride corrosion. The diffusion of chloride ions, which are the strongest steel depassivating agent, occurs faster than $\mathrm{CO}_{2}$ diffusion and the reinforcement corrosion is rapid [2, 3, 5, 11-13].

The risk of chloride corrosion due to the use of de-icing agents is often additionally associated with the frost and repeated freezing and thawing actions of structural elements. The liquid freezing in the pores of concrete increases its volume, which causes the increase of internal stresses and leads to cracks in the concrete cover increasing the diffusion of chlorides [2, 3, 14-15]. In order to reduce this phenomenon the introduction of air-entraining admixture is beneficial [3,14-17]. As a result of air-entraining in the concrete the air bubbles occur (which are not completely filled with water) which absorb the water excess from the capillary pores during ice crystallization. In addition, the air voids are the place where certain chemical reaction products are deposited, so that no stresses can be created that can damage the concrete structure [14].

Often, durability tests are limited either to material tests of the concrete itself or to assess the degree of reinforcement corrosion in the structural elements [18-20]. This article presents both the results of electrochemical tests of the reinforcement corrosion activity based on the measurements of the corrosion current density and the results of material tests, including the determination of the mineral concrete composition. The tests allow comprehensively to assess the effect of air-entrained concrete with blast-furnace slag cement on the degree of reinforcement corrosion risk in concrete caused by the simultaneous action of chlorides and frost.

\section{Materials and test methods}

Twelve reinforced concrete specimens with dimensions $210 \times 228 \times 100 \mathrm{~mm}$ were prepared for the tests. Based on the standard recommendations placed in Eurocode 2 [21] regarding the design of the structure in accordance with the accepted construction class and exposure class, it was assumed that the elements subjected to 50 years of durability, exposed to chlorine corrosion and aggressive impact of freezing - thawing. In connection with the above, specimens were made of concrete class C $30 / 37$, consistency S-3, with a water / cement ratio $\mathrm{w} / \mathrm{c}=0.43$. The components of a concrete mix for $1 \mathrm{~m}^{3}$ are included in table 1 .

Table 1. Components of the $\mathrm{C} 30 / 37$ concrete mix for for $1 \mathrm{~m}^{3}$.

\begin{tabular}{|c|c|}
\hline Ingredients & Amount \\
\hline $\begin{array}{c}\text { blast-furnace slag cement CEM III/A } 42.5 \mathrm{~N}- \\
\text { LH/HSR/NA }\end{array}$ & $384\left[\mathrm{~kg} / \mathrm{m}^{3}\right]$ \\
\hline aggregate I - basalt grit f $2 / 8 \mathrm{~mm}$ & $600\left[\mathrm{~kg} / \mathrm{m}^{3}\right]$ \\
\hline aggregate II - basalt grit f $8 / 16 \mathrm{~mm}$ & $650\left[\mathrm{~kg} / \mathrm{m}^{3}\right]$ \\
\hline mine sand & $680\left[\mathrm{~kg} / \mathrm{m}^{3}\right]$ \\
\hline water - water supply & $166[1]$ \\
\hline
\end{tabular}




\begin{tabular}{|c|l|}
\hline plasticizer - Adva Flow 440 & $0.6 \%$ of cement volume \\
\hline air-entraining admixture - Darex AEA W (LP) & $0.5 \%$ of cement volume \\
\hline
\end{tabular}

The tests were carried out on two groups of reinforced concrete specimens subjected to freezing and thawing cycles in $3 \% \mathrm{NaCl}$ solution to initiate chloride corrosion, one group (6 pieces) were specimens with air-entraining admixture and the other group (6 pieces) were specimens without air-entraining admixture. The air content in the specimens was $3.5 \%$. ( $0.5 \%$ of cement volume). Two parallel ribbed bars with a diameter of $\mathrm{mm} 8 \mathrm{~mm}$ made of BST 500 steel were placed in each specimen. The bars were placed in a spacing of $70 \mathrm{~mm}$ from the specimen side edges. The specimens after 7 days of ripening were disassembled and kept in water for a period of 14 days. After being removed from the water, the specimens were stored at a temperature of $20^{\circ} \mathrm{C} \pm 2{ }^{\circ} \mathrm{C}$, and a relative humidity of $50 \% \pm 5 \%$. Then, selected electrochemical and material tests were performed.

The electrochemical measurements were performed in two stages: stage I - recursive measurements made on all specimens S0 and SA (reference to later measurements); stage II - measurements on the same specimens made after 120 cycles of freezing and thawing in $3 \%$ $\mathrm{NaCl}$ solution in order to initiate corrosion processes on the reinforcement. Specimens S0 and SA were subjected to freeze-thaw cycles in a frost resistance test chamber with an automatically controlled test program. During the freezing cycles, the specimens were completely immersed in the solution. The temperature range was $+18^{\circ} \mathrm{C} \div-18^{\circ} \mathrm{C}$. During the day $\sim 3$ cycles took place. During the freeze-thaw cycles the reinforcement bars protruding from the specimens were insulated and had no contact with the solution. The protruding rods were tightly wrapped with several layers of insulation (with parameters guaranteeing its effectiveness at a temperature of $-40^{\circ} \mathrm{C}$ to $+105^{\circ} \mathrm{C}$ and in an aggressive environment) and sealed with grease. The photo of the specimen with the connected electrochemical measurement set is shown in Figure 1.

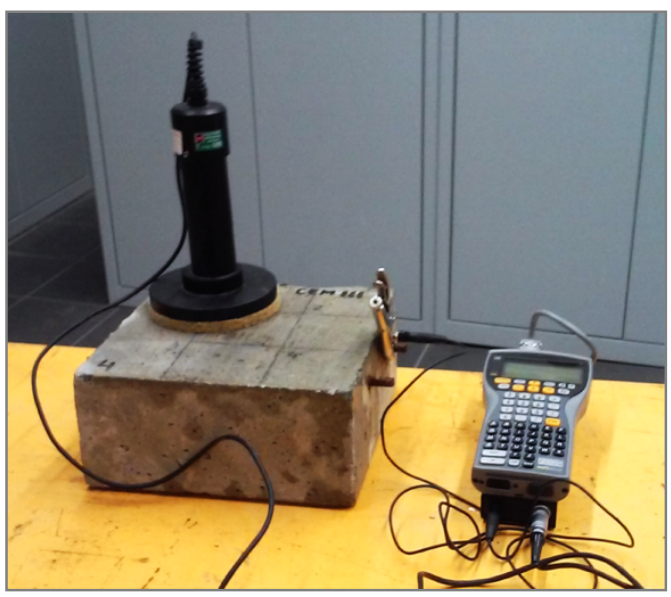

Fig. 1. Photograph of the reinforced concrete specimen with the galvanostatic pulse apparatus.

Electrochemical tests were carried out using the galvanostatic pulse method. This is one of the non-destructive testing methods described e.g. in [4, 13, 18-20, 22]. This method uses the fact that the corrosion process of reinforcement in concrete is an electrochemical process, and the measurements of some electrical parameters referenced to the base results $[18,22]$ allow to indirect assess the progress of steel corrosion in concrete. As part of the galvanostatic pulse tests, the measurements of the corrosion current density, i.e. the most important and the most reliable parameter were made. In both stages measurements of the corrosion current density on the specimens were carried out in accordance with the guidelines given in [22]. 
On each specimen measurements were made at four measurement points located regularly over reinforcing bars (two points above each bar), and the obtained results were compared to the base results [22] according to which reinforcement corrosion activity is determined as follows:

- $\mathrm{i}_{\text {cor }}<0.5\left[\mu \mathrm{A} / \mathrm{cm}^{2}\right]-$ not forecasted corrosion activity,

- $\mathrm{i}_{\text {cor }}=0.5 \div 2.0\left[\mu \mathrm{A} / \mathrm{cm}^{2}\right]$ - irrelevant corrosion activity,

- $\mathrm{i}_{\text {cor }}=2,0 \div 5.0\left[\mu \mathrm{A} / \mathrm{cm}^{2}\right]-$ low corrosion activity,

- $\mathrm{i}_{\text {cor }}=5.0 \div 15.0\left[\mu \mathrm{A} / \mathrm{cm}^{2}\right]-$ moderate corrosion activity,

- $i_{\text {cor }}>15.0\left[\mu \mathrm{A} / \mathrm{cm}^{2}\right]-$ high corrosion activity.

Material tests included determining the phase composition of the concrete by X-ray diffraction analysis of specimens S0 and SA after freeze-thaw cycles dissociated from the layer at the reinforcing bar. The phase composition of concretes was performed by X-ray powder diffraction using PANanalytical Empyrean diffractometer. In addition, the microstructure of both specimens ( $\mathrm{S} 0$ and $\mathrm{SA}$ ) was observed under scanning electron microscopy (SEM). The microstructure examination was conducted under scanning electron microscope FEI Company Quanta FEG 205 coupled with the X-ray microanalyser (EDS).

\section{Research results and discussion}

On the basis of electrochemical tests, after the results of measurements of the corrosion current density to the base of the standard results, it was possible to determine the corrosion activity of the specimens' reinforcement. The results from all measuring points on all specimens were pre-analysed [23]. Then, one measurement point was separated from each specimen, in which the values of corrosion current density were the highest after the second phase of measurements. This point in each specimen determined the degradation degree of the whole specimen. In the further part of the research, the results obtained at these points were analyzed and compared as representative for the whole specimen.

In stage I of the tests, the values of corrosion current density measured on all specimens S0 and SA did not exceed $i_{\text {cor }}=2 \mu \mathrm{A} / \mathrm{cm}^{2}$ (Fig. 2), which in reference to the given criterion, indicated "irrelevant corrosion activity of the reinforcement". Based on the results of the corrosion current density made in stage II (i.e. after 120 cycles of freezing and thawing the specimens in $3 \% \mathrm{NaCl}$ ), it can be seen that in all specimens S0 (without air-entraining admixture) the density of the corrosion current density increased noticeably, and, $\mathrm{i}_{\text {cor }}=6.42$ $\div 9.73 \mu \mathrm{A} / \mathrm{cm}^{2}$, which was indicative of "moderate reinforcement corrosive activity" (Fig. 2). Whereas in specimens SA (with air-entraining admixture), although subject to the same freezing and thawing cycles and chlorides, the density of corrosion current density increased only slightly: in four specimens it did not exceed $\mathrm{i}_{\text {cor }}=2 \mu \mathrm{A} / \mathrm{cm}^{2}$, and in two specimens it reached $i_{\text {cor }}=3.86 \mu \mathrm{A} / \mathrm{cm}^{2}$ (Fig. 2) and nowhere exceeded the limit of" low reinforcement corrosion activity". 


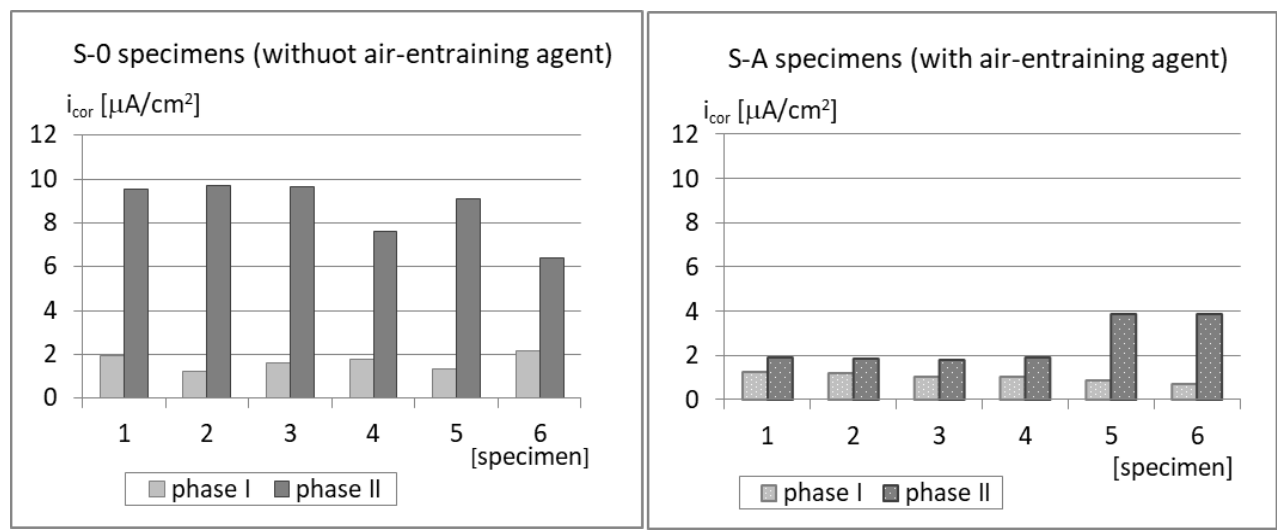

Fig. 2. Results of corrosion current density measurements made on specimens S0 (without airentraining admixture) and SA (with air-entraining admixture) in two stages of research: stage I recurrent measurements, stage II - measurements carried out after 120 freezing and thawing cycles in $3 \% \mathrm{NaCl}$ solution.

Analysis of the phase composition of concrete taken from the specimen indicated a low Friedel salt content. Intensity of peaks at an angle of $11,2^{\circ} 2 \theta$ in specimens taken from airentrained and non-air-entrained concrete were comparable. It can therefore be assumed that chloride ions were associated to a similar degree. The low Friedel salt content in the analysed concretes may have resulted from the limitation of the $\mathrm{C}_{3} \mathrm{~A}$ phase content in the cement high sulphate resistant (HSR). Friedel salt in this case is formed as a result of the reaction of aluminates being components of blast furnace slag and chloride ions derived from $\mathrm{NaCl}$ dissociation [3]. In addition, it should be noted that a small number of chloroaluminate phases are the result of penetration of chlorides into hardened concrete, i.e. the $\mathrm{C}_{3} \mathrm{~A}$ phase has already been bound in the form of sulfoaluminate. In this case, chloride ions penetrating the concrete structure can be absorbed by the C-S-H phase, which is formed in increased amounts when blast-furnace slag cement is used. An analysis of the phase composition of air-entrained and non-air-entrained concretes is shown in Figure 3.

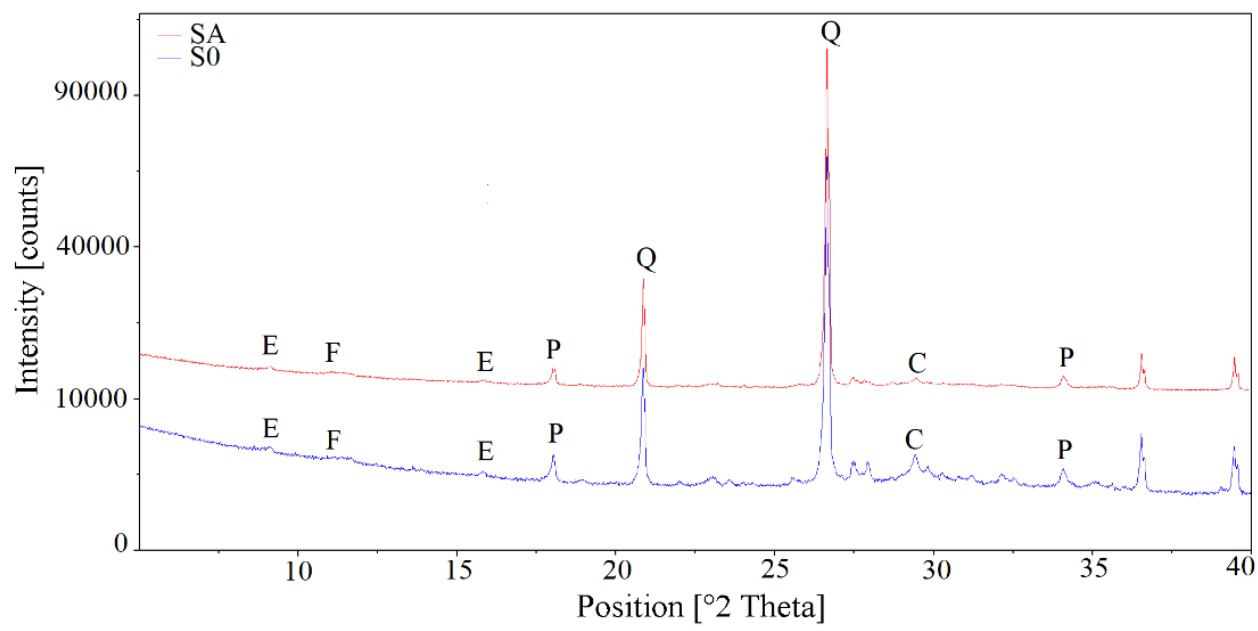

Fig. 3. Diffractogram of the concrete specimens with aeration admixture SA and without aeration admixture S0, after freeze-thaw cycles in the reinforcing bar, E-ettringite, F- Friedel salt, P-portlandyt, C- calcite, Q- quartz. 
The presence of Friedel salt in the analysed concretes was also confirmed by the SEMEDS analysis. Figure 4 shows a photo from a scanning microscope with visible Friedel salt crystals in concrete together with EDS analysis.
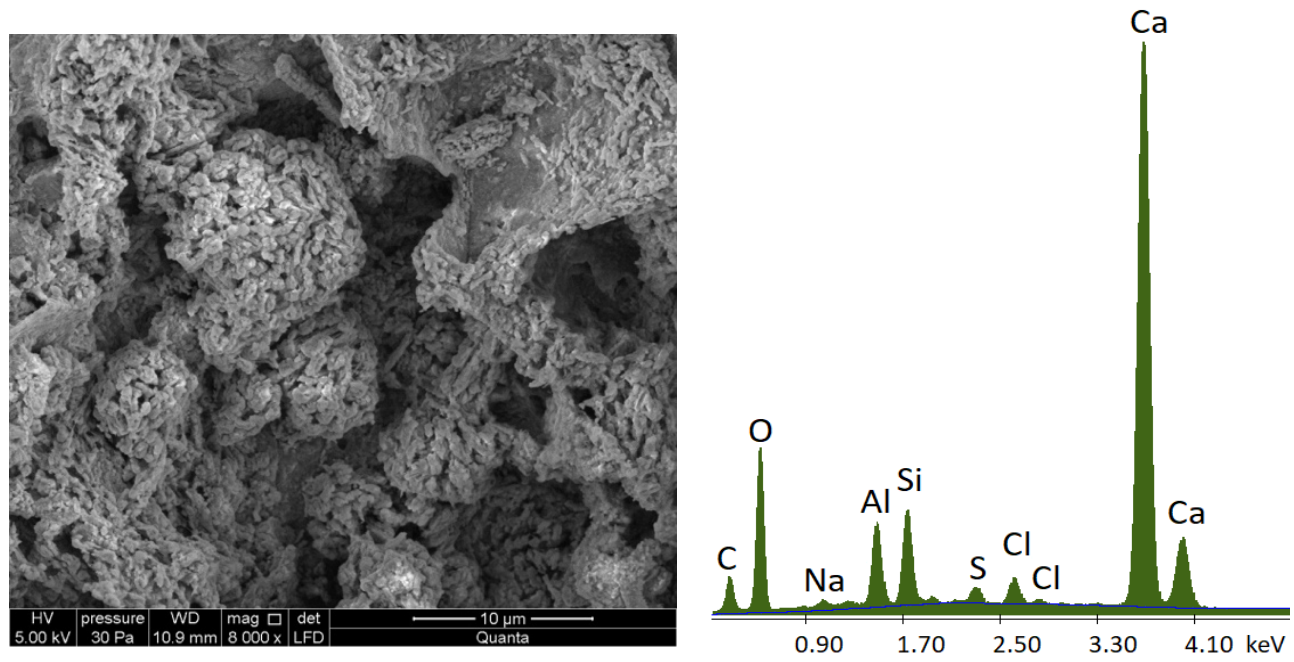

Fig. 4. Friedel salt crystals in concrete together with EDS analysis.

Increased susceptibility of non-aerated concrete, subjected to freezing and thawing cycles in chloride solution, can be explained by changes in the microstructure resulting from the susceptibility of concrete to frost corrosion. Observations of the microstructure of non-airentrained concrete specimens indicate a higher number of micro cracks compared to airentrained concretes (Fig. 5).

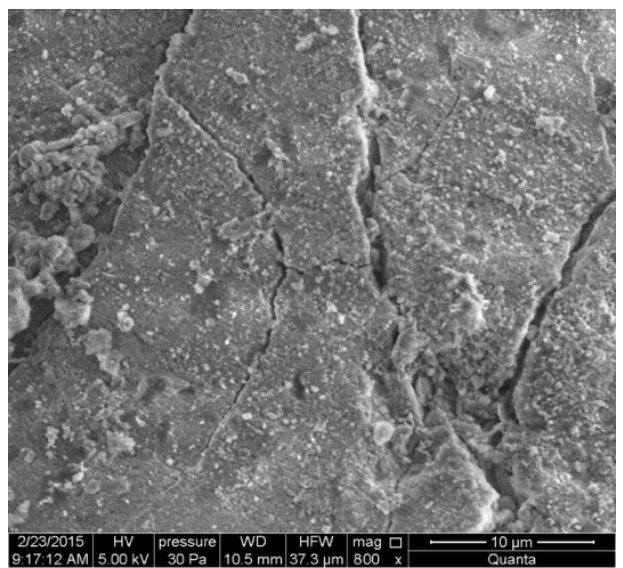

a)

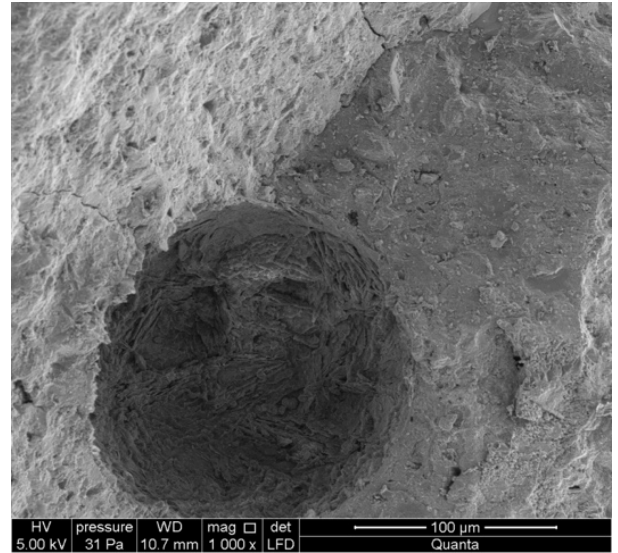

b)

Fig. 5. Microstructure of concrete after freezing and thawing cycles: a) non-air-entraining concrete, b) air-entraining concrete.

Based on electrochemical analysis it was found that in non-air-entraining concrete after freeze-thaw cycles the density of the corrosive current increased more than in the aerated concrete, despite the small differences in phase composition of air-entrained and non-airentrained concrete. In aerated concrete, $\mathrm{Cl}^{-}$ions could be adsorbed on the pore walls, some chloride ions are immobilized, so it does not participate in the diffusion process [24]. In addition, the absorbed chlorides have noncrystalline nature so they would be not show in X- 
ray diffraction [25]. Analysis of microstructure shows that the damage caused by freezing and thawing in aerated concrete was smaller. This is due to the fact that the dispersed air bubbles absorb the internal pressure increase caused by freezing, which reduces the damage. A smaller number of micro cracks in aerated concrete means less penetration of chlorides into the concrete interior, due to the reduction of the number of potential penetration routes and the same reduction of steel corrosion, which was observed by other researcher [26]. As Zhang and co-workers indicate, the absorption coefficient of chlorides in aerated concrete is smaller compared to non-aerated concrete. In non-aerated concrete, this coefficient increases in proportion to the number of freezing and thawing cycles. In aerated concrete, this ratio is reduced due to the material's characteristic structure [27].

\section{Conclusions}

On the basis of tests carried out on reinforced specimens with aerated and non-aerated CEM III/A cement, which were subjected to 120 freezing and thawing cycles in $3 \% \mathrm{NaCl}$, it was concluded that:

1. Based on the measurements of the corrosion current density, it was found that in S0 specimens (without air-entraining admixture) the corrosion activity of the reinforcement after 120 cycles of freezing and thawing specimens in $3 \% \mathrm{NaCl}$ increased by $7,07 \mu \mathrm{A} / \mathrm{cm}^{2}$, on average, while in SA specimens (with air-entraining admixture) only by $1,51 \mu \mathrm{A} / \mathrm{cm}^{2}$.

2. Analysis of phase composition of hardened concrete did not show significant differences in aerated and non-aerated concrete.

3. Increased corrosion activity of reinforcement in non-air-entrained concrete specimens, subjected to cycles of freezing and thawing in a chloride solution, results from changes in the microstructure of concrete caused by frost corrosion.

4. In order to increase the resistance of reinforced concrete to the simultaneous action of chloride and frost corrosion, it is necessary to use both blast-furnace slag cement as well as an air entraining admixture.

\section{References}

1. L. Czarnecki, P.H. Emmons, Naprawa i ochrona konstrukcji betonowych (SPC, Kraków, 2002)

2. Z. Ściślewski, Ochrona konstrukcji żelbetowych (Warszawa, Arkady 1999)

3. W. Kurdowski, Chemia cementu i betonu (SPC, Kraków, 2010)

4. A. Zybura, M. Jaśniok, T. Jaśniok, Diagnostyka konstrukcji żelbetowych. Badania korozji zbrojenia i właściwości ochronnych betonu (PWN, Warszawa 2011)

5. X.M. Shi, N. Xie, K.J. Fortunate, J. Gong, Constr. Build. Mater. 30, 125 (2012)

6. S. Ahmad, Cem. Concr. Comp. 25, 459 (2003)

7. J. Małolepszy, Trwałość betonów z cementów żużlowych, 225-243, (Con., Wisła, 2002)

8. J. Deja, Cement Lime Concrete 74, 280-283 (2007)

9. Z. Giergiczny, Eng. Bull. 67, 275-279 (2010)

10. W. Grzmil, Z. Owsiak, Cem. Lime Concr. 80, 137-144 (2013)

11. W. Kurdowski, Cem. Lime Concr. 69, 56-60, (2002)

12. T. Jaśniok, B. Słomka-Słupik, A. Zybura, Cem. Lime Concr. 81, 158-165 (2014) 
13. W. Grzmil, W. Raczkiewicz, Cem. Lime Concr. 84, 311-319 (2017)

14. Z. Rusin, Technologia betonów mrozoodpornych (SPC, Kraków, 2002)

15. L. Czarnecki, J. Deja, K. Flaga, W. Kurdowski, J. Małolepszy, W. Radomski, J. Śliwiński, Budownictwo, Technologie, Architektura 69, 66-69 (2015)

16. J. Deja, Cem. Lime Concr. 74, 280-283 (2007)

17. J. Deja, Cem. Concr. Comp. 25, 357-361 (2003)

18. W. Raczkiewicz, D. Michałowska - Maziejuk, Structure and Environment 4, 21-27, (2012)

19. B. Elsner, et al, International Conference Repair of Concrete Structures (Svolvaer, Norway, 1997)

20. H.E. Sørense, T. Frølund, Int. Conference on Concrete in Marine Environment (Hanoi, 2002)

21. EN 1992-1-1 (2004)

22. http://www.germann.org/TestSystems/GalvaPulse/GalvaPulse.pdf (January, 2018)

23. W. Raczkiewicz, Advances in Materials Science (to be published)

24. R. Cerny, Z. Pavlık, P. Rovnanıkova, Cem. Concr. Compos. 26, 705 (2004)

25. L. Bertolini, B. Elsener, P. Pedeferii, R. Polder, Corrosion of Steel in Concrete: Prevention, Diagnosis, Repair (WILEY-VCH Verlag GmbH\&Co.KGaA, 2005)

26. Z. Fangzhi, M. Zhiming, Z. Tiejun, Adv. Mat. Sc. Eng. 16 (2016)

27. P. Zhang, Y. Cong, M. Vogel, Z. Liu, H.S. Muller, Y. Zhu, T. Zhao, Con. Build. Mat. 148 (2017) 